\title{
Barriers and facilitators of access to maternal services for women with disabilities: scoping review protocol
}

Doreen Mheta and Tivani P. Mashamba-Thompson ${ }^{*}$

\begin{abstract}
Background: The Sustainable Development Goals (SDGs) emphasises the increasing equitable coverage of quality health care and provision of integrated services as means of reducing maternal mortality. Despite so much effort being placed on improved access to maternity health care, studies show that women with disabilities are being systemically excluded from the mainstream maternal health services. The proposed scoping review aims to map literature on the barriers and facilitators of access to maternal services for women with disabilities.

Methods and analysis: The search strategy for this scoping review study will involve electronic databases including Pubmed, MEDLINE via EBSCOhost, CINAHL Plus with full text via EBSCOhost, Africa-Wide Info via EBSCOhost, JSTOR and Proquest Health and Medical Complete. Articles will also be searched through the "Cited by" search as well as citations included in the reference lists of included articles. A two-stage mapping strategy would be conducted. Stage 1 would be to screen studies through examining their titles. Furthermore, we will screen abstracts of the identified studies descriptively and by focus and method as stipulated by the inclusion and exclusion criteria. In stage 2, we will extract data from the included studies. A parallel screening and data extraction will be undertaken by two reviewers. We will access the quality of the included studies using the mixed methods appraisal tool (MMAT). We will use NVIVO version 10 to extract the relevant outcomes and thematic analysis of the studies.

Discussion: We anticipate to find relevant studies reporting evidence on the barriers and facilitators of access to maternal health services in Sub-Saharan Africa. The evidence obtained from the included studies when summarised will help guide future research. The study findings will be disseminated electronically and in print. In addition, it will be presented at conferences related to sexual reproductive health, maternal health care and reproductive health.
\end{abstract}

Keywords: Maternal health, Disability, Health care, Access, Sub-Saharan Africa

\section{Background}

Maternal health is a global health priority which emphasises the reduction of maternal mortality in developing countries. The recently adopted Sustainable Development Goals (SGDs) focuses on increasing equitable coverage of quality health care and provision of integrated services as means to reduce maternal mortality [1]. Most governments in Sub-Saharan Africa are prioritising maternal health $[2,3]$. However, the majority of the countries in this region are faced with poor referral systems, shortages of skilled health personnel and poor transport infrastructure

\footnotetext{
* Correspondence: Mashamba-Thompson@ukzn.ac.za

Discipline of Public Health Medicine, School of Nursing and Public Health, University of KwaZulu-Natal, Durban 4001, South Africa

[4]. While most developed countries and some low and middle income countries (LMICs) experienced some declines in maternal mortality ratios, most of the countries in Sub-Saharan regions still experience high maternal mortality rates [5]. As a result, Sub-Saharan Africa did not achieve the millennium development goal of reducing maternal mortality by $75 \%$ [6].

South Africa is one of the developing countries that are in the forefront in the prioritising of maternal health through increasing primary health care clinics [3]. This is evidenced by the removal of user fees for maternal and child health services at the levels of primary health care and district hospital [7]. Despite these measures being put in place, women particularly the vulnerable and disadvantaged still face numerous challenges in accessing these services in 
South Africa [8]. While the factors that militate against maternity services for women in general are well documented in Sub-Saharan Africa, there is little research that documents the factors that inhibit or enhance access to maternity and child services for women with disabilities [9-11]. Though there are numerous definitions of disabilities, in this review, disabilities will refer to long-term visual, hearing, mental and physical impairment [8].

Access to health care is a complex phenomenon which is influenced by multiple factors. Disparities in access to health result in adverse health outcomes, thus posing a public health problem [12]. There is no single definition of access to health care services; however, a comprehensive view of access pertains to the dimensions of availability, accessibility, accommodation, affordability and acceptability [13]. For this review, access to maternal health will be explored through the availability, affordability, acceptability and quality of the services [13]. Some of the challenges that are specifically faced by women with disabilities include survival rates, maternal mortality and morbidity, accessing information on sexual reproductive health, family planning services, and prenatal and post natal services [14]. In addition, research reveals that women with disabilities have higher pregnancy complications, preterm deliveries and low birth infants [15]. Despite that there is a growing recognition that health systems should develop appropriate and accessible maternal health care services for women with disabilities [11, 14, 16], there is paucity of evidence on the experiences of women with disabilities on accessing maternal health care services [16].

The existing literature indicates that there is a need to understand the barriers and facilitators of access to maternal services as well as the different models of maternity health care services that could facilitate choices for women with disabilities [17]. Moreover, there is a need for strategies to improve access to maternal health care services for this population [14]. This may facilitate the development of horizontal approaches towards the reduction of maternal mortality in Sub-Saharan Africa. This scoping review therefore aims at mapping literature on the barriers and facilitators of access to maternal health care services for women with disabilities. The objectives of this scoping review are as follows:

$\triangleright$ To review published literature on the barriers and facilitators of access to maternal health services for women with disabilities

$\triangleright$ To review the literature on existing maternity health care models for women with disabilities

$>$ To review literature on the existing interventions to improve access to maternity health care for women with disabilities
The findings from this study will enable the researchers to examine the extent and range and nature of research activity on the barriers and facilitators of access to maternity services for women with disabilities. In addition, the findings will enable the researchers to identify the different maternity health care models and interventions that improve access to maternal health care services.

\section{Methodology \\ Scoping review}

We will conduct a scoping review of peer-reviewed literature on the barriers and facilitators of access to maternal services for women with disabilities. A scoping review method was selected as it facilitates the mapping of new concepts, types of evidence and gaps related [18]. For the proposed review, we would be guided by Arksey and O'Malley framework [19]. The framework involves (i) identifying the research question, (ii) identifying relevant studies, (iii) study selection, (iv) charting the data, and (v) collating, summarising and reporting results.

\section{Identifying the research question}

The research question is what is known from the existing literature about the barriers and facilitators of access to maternal health services in Sub-Saharan Africa?

The sub-research questions are as follows:

1. What are the existing models of maternal health care services in Sub-Saharan Africa?

2. What are the available interventions for facilitating access to maternal services for women with disabilities in Sub-Saharan Africa?

\section{Eligibility of research question}

The study will use an amended PICOS (Population, Intervention, Comparison, Outcomes and Study setting) framework to determine the eligibility of the research question (Table 1).

\section{Identifying relevant studies}

Primary studies that have a clear empirical base utilising qualitative, quantitative and mixed methods published in peer-reviewed journals as well as in grey literature that address the research question will be included. All study designs would be included. An electronic search will be conducted in the following electronic databases: MEDLINE/Pubmed, CINAHL Plus with full text (EBSCO) and Africa-Wide information, Google Scholar and Proquest. Websites such as the World Health Organisation (WHO), UNICEF and governmental websites would be searched for policies and reports on access to maternal services for women with disabilities. Studies will be identified by searching literature that was published in any language and those 
Table 1 PICOS framework for determination of eligibility of review question

\begin{tabular}{ll}
\hline Criteria & Determinants \\
\hline Population & $\begin{array}{l}\text { The population of this study will be women with } \\
\text { disabilities (that is, visual, hearing, mental and physical } \\
\text { impairment) who are seeking maternal health care } \\
\text { services (antenatal, perinatal and immediate post- } \\
\text { partum). }\end{array}$ \\
Intervention & $\begin{array}{l}\text { Access to maternal health care services (antenatal, } \\
\text { perinatal and immediate post-partum) }\end{array}$ \\
Comparison & $\begin{array}{l}\text { Women without disabilities } \\
\text { Outcomes }\end{array}$ \\
Study setting & $\begin{array}{l}\text { Access to maternal health care services } \\
\text { Sub-Saharan Africa }\end{array}$ \\
& $\begin{array}{l}\text { While the review focuses mainly on studies from Sub- } \\
\text { to maternal services for women with disabilities in this }\end{array}$ \\
& $\begin{array}{l}\text { region, the setting has been opened to include studies } \\
\text { from all over the world. }\end{array}$
\end{tabular}

studies that are translatable to English from January 2000 to December 2015.

Articles will also be searched through the "Cited by" search as well as citations included in the reference lists of included articles. The search terms will include maternal health, disability, health care, access, and Sub-Saharan Africa. Database-specific thesaurus terms (e.g. $\mathrm{MeSH}$ terms) as well as free-text terms will be used to search articles. After searching, the studies will be screened against the inclusion and exclusion criteria.

\section{Study selection}

The eligibility criteria were developed to ensure that the included studies contain the specific information needed to answer the research question on the barriers and facilitators of access to maternal health care services for women with disabilities.

\section{Eligibility criteria}

\section{Inclusion criteria}

For studies to be included, they should meet the following criteria:

- There would be no language restriction.

- Focus on women with disabilities seeking maternal health care services.

- Published from January 2000 to December 2015.

- Report on experiences of women with disabilities when accessing maternal health care services.

\section{Exclusion criteria}

Studies will be excluded if they meet the following characteristics:

- Studies which do not have women with disabilities as part of the study population focus on women with disabilities seeking health care services other than maternal health care services: This review will exclude studies that have women without disabilities as the population of interest due to the fact that women with disabilities have their own challenges that are specific to them. Studies that report on women without disabilities may not bring out the barriers and facilitators of access to maternal services specific to women with disabilities

- Studies that report on drug and procedural interventions and

- Studies that are published before January 2000 and after December 2015: Studies conducted during the year 2016 as it is now a new era of the SDGs whereas during the years 2000 to 2015, it was the MDG era. Studies publish after December may have another focus which is completely different from the one in the MDG era. Furthermore, before 2000, the emphasis on reducing maternal deaths by three quarters did not exist and the Convention on the Rights of Persons with Disabilities (CRPD) had not been adopted by the United Nations. As result, the issues of women with disabilities were not emphasised as they were after 2006.

The search strategies will be piloted to check the appropriateness of the selected databases and key words. Articles will be searched from the databases by one reviewer who will share the Endnote library with the second reviewer. The two reviewers will conduct a comprehensive title screening guided by the eligible criteria. All eligible studies will be exported into EndNote X7.5 reference management software. EndNote X7 program will be used to check for duplication of articles and to delete the duplicated articles. Table 2 below illustrates how the electronic data search will be recorded.

Abstracts and full articles of the included studies will be screened for eligibility. This will be conducted independently by two reviewers to identify study analysis and assessment. Where there is no agreement between the two reviewers, the studies will be passed on to a third reviewer for consideration. We will seek for assistance from the UKZN library services for articles that are difficult to find. We will also write to the authors to ask for papers in cases of difficult to find articles. Table 4 in the appendix presents the results of the pilot search.

Table 2 Electronic search record Keyword search Search engine used Number of publications retrieved 
The study selection procedure will be summarised using a PRISMA chart as indicated in Fig. 1.

\section{Charting the data}

An analytical method would be utilised to extract the background information and process oriented information of each included study. A data charting form would be developed and piloted. The variables and themes to include in order to answer the question will be determined as indicated in Table 3. The data charting form will be constantly updated.

\section{Collating, summarising and reporting of results}

The aim of this study is to map the existing evidence and to summarise the findings as presented across articles. A narrative account of the data extracted from the included studies will be analysed using the thematic content analysis. Data will be extracted around the following outcomes: models of maternity health care services, barriers of access to maternity health care services, and facilitators of access to maternal health care services. Emerging themes will also be coded. NVIVO software version 10 would be utilised collectively to code the data from the included studies based on the above categories [20]. The below process would be followed;
Table 3 Data charting form

Author and date

Study title

Journal full reference

Aims or research question

Participant characteristics

Recruitment context (e.g. where people were recruited).

Sampling method

Study design

Theoretical background

Data collection (what data collection methods were used?)

Data analysis (how was the data analysed?)

Intervention

Intervention outcome

Most relevant findings

Conclusions

Comments

- Coding data from the included articles

- Categorising the codes into major themes

- Displaying the data

- Identifying key patterns in the data and identify subthemes

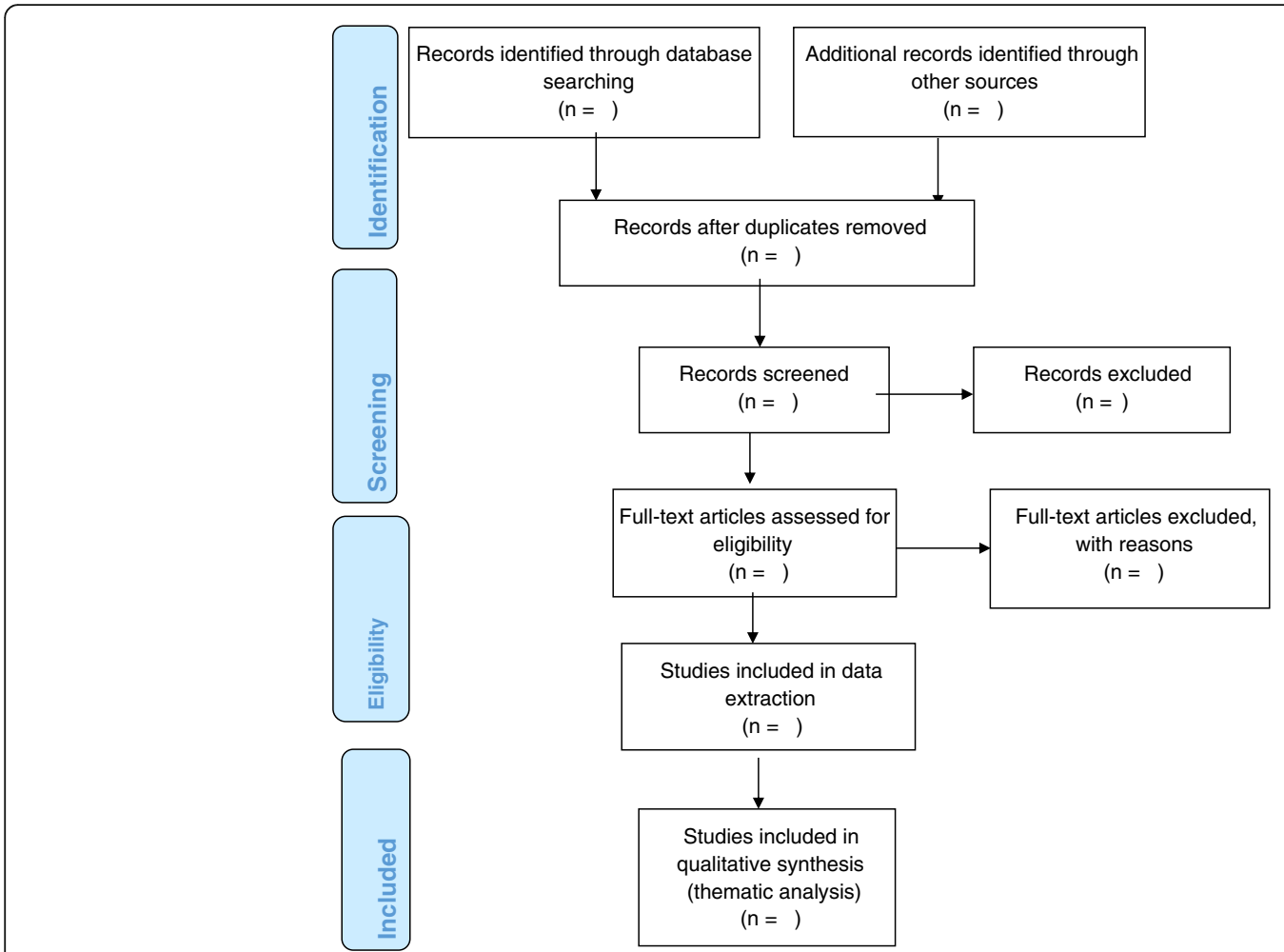

Fig. 1 Study selection procedure 
- Summarising

\section{Synthesis}

We will analyse the resulting themes and critically examine their relationship to the research question. The reviewers will also analyse the meanings of the findings in relation to the aim of the study and the implications of these findings for future research, policy and practice.

\section{Quality appraisal}

The quality of the studies will be determined through study appraisal using the mixed method appraisal tool (MMAT)-Version 2011 [21]. The tool will be utilised to examine the appropriateness of the aim of the study, adequacy and methodology, study design, participant recruitment, data collection, data analysis, presentation of findings, authors' discussions and conclusions. The quality of the article will be determined from the examination of the above mentioned aspects.

\section{Discussion}

The scoping review will be conducted as a first part of the study on the barriers and facilitators of access to maternity services for women with disabilities in South Africa. The review is aimed mapping the existing evidence and summarising the findings as presented across the studies on the barriers and facilitators of access to maternal health care services for women with disabilities. In addition, the review will on identify the existing maternity models and interventions that enhance access to maternal health care services for women with disabilities. Despite that there is a growing recognition that health systems should develop appropriate and accessible maternal health care services for women with disabilities $[11,14,16]$, there is paucity of evidence on the experiences of women with disabilities on accessing maternal health care services [16]. In order to enable development of disability friendly maternal health care services, there is a need to explore the maternal health care needs, barriers and facilitators of access to maternal services for women with disabilities especially in low and middle income countries [15].

Studies that report on drugs and procedural interventions would be excluded because focus of this review is on access to maternal health services. Most maternal deaths could be avoided if the quality maternal health care services are available to those who need the services. Therefore, this review excludes studies that report on drug and procedural interventions as the main focus is on access (availability, affordability, acceptability and quality of the services). The studies on drug and procedural interventions report on women with disabilities who have already accessed the services and the intervention is not the focus of this study.

The findings of this study may be of interest to policy makers and stakeholders involved in the provision of maternal health care services, and stakeholders advocating for equity of access and health systems strengthening. In addition, the findings of this study will be of interest to researchers by highlighting gaps in evidence that may require further investigation.

\section{Appendix}

Table 4 Results of the pilot database search

\begin{tabular}{|c|c|c|c|}
\hline Keyword search & $\begin{array}{l}\text { Date of } \\
\text { search }\end{array}$ & $\begin{array}{l}\text { Search } \\
\text { engine used }\end{array}$ & $\begin{array}{l}\text { Number of } \\
\text { publications } \\
\text { retrieved }\end{array}$ \\
\hline $\begin{array}{l}\text { ((“"disabled persons"[MeSH } \\
\text { Terms] OR ("disabled"[All } \\
\text { Fields] AND "persons"[All } \\
\text { Fields]) OR "disabled } \\
\text { persons"[All Fields] OR } \\
\text { "disabled"[All Fields]) AND } \\
\text { ("women"[MeSH Terms] OR } \\
\text { "women"[All Fields])) AND } \\
\text { (access[All Fields] AND } \\
\text { ("maternal health } \\
\text { services"[MeSH Terms] OR } \\
\text { ("maternal"[All Fields] AND } \\
\text { "health"[All Fields] AND } \\
\text { "services"[All Fields]) OR } \\
\text { "maternal health } \\
\text { services"[All Fields] OR } \\
\text { ("maternal"[All Fields] AND } \\
\text { "health"[All Fields] AND } \\
\text { "care"[All Fields]) OR } \\
\text { "maternal health care"[All } \\
\text { Fields]) AND services[All } \\
\text { Fields])) OR (models[All } \\
\text { Fields] AND ("maternal } \\
\text { health services"[MeSH } \\
\text { Terms] OR ("maternal"[All } \\
\text { Fields] AND "health"[All } \\
\text { Fields] AND "services"[All } \\
\text { Fields]) OR "maternal health } \\
\text { services"[All Fields])) AND } \\
\text { (("loattrfull text"[sb] AND } \\
\text { hasabstract[text] AND } \\
\text { "loattrfree full text"[sb]) } \\
\text { AND ("2000/01/01"[PDAT] : } \\
\text { "2015/12/31"[PDAT]) AND } \\
\text { "humans"[MeSH Terms]) }\end{array}$ & $\begin{array}{l}11 \text { April } \\
2017\end{array}$ & $\begin{array}{l}\text { MEDLINE via } \\
\text { Pubmed }\end{array}$ & 1115 \\
\hline
\end{tabular}




\section{Abbreviations}

CRPD: Convention on the Rights of Persons with Disabilities; LMIC: Low and middle income countries.; MDG: Millennium development goals; MMAT: Mixed methods appraisal tool; PICOS: Population intervention outcomes study setting; SDG: Sustainable Development Goals

\section{Acknowledgements}

The authors would like thank the College of Health Sciences, University of KwaZulu-Natal for financially supporting the development of this research study.

\section{Funding}

The University of KwaZulu-Natal College of Health Sciences PhD Scholarship funded this research study.

\section{Availability of data and materials}

All data generated or analysed during this study will be included in the published scoping review article

\section{Author's contributions}

DM conceptualised the study and prepared the draft proposal under the supervision of TPM-T. Both DM and TPM-T contributed to the development of the background and planned output of the research as well as the design of the study. TPM-T contributed to the development of the methods relating to the review and synthesis of data including the sifting and data extraction process. DM prepared the manuscript, and TPM-T reviewed it. Both authors (DM and TPM-T) contributed to the reviewed draft version of the manuscript and approved the final version.

\section{Competing interests}

The authors declare that they have no competing interests.

\section{Consent for publication}

Not applicable.

\section{Ethics approval and consent to participate}

Not applicable.

\section{Publisher's Note}

Springer Nature remains neutral with regard to jurisdictional claims in published maps and institutional affiliations.

Received: 17 February 2017 Accepted: 3 May 2017

Published online: 16 May 2017

\section{References}

1. Regmi P, Van Teijlingen E, Hundley V, Simkhada P, Sharma S, Mahato PK. Sustainable Development Goals: relevance to maternal and child health in Nepal. Health Prospect: J Public Health. 2016;15(1):9-10.

2. Kinney MV, Kerber KJ, Black RE, Cohen B, Nkrumah F, Coovadia H, et al. SubSaharan Africa's mothers, newborns, and children: where and why do they die? PLoS Med. 2010;7(6):e1000294.

3. Chopra M, Daviaud E, Pattinson R, Fonn S, Lawn JE. Health in South Africa 2. Saving the lives of South Africa's mothers, babies, and children: can the health system deliver? LANCET. 2009:374(9692):835-46.

4. Kyei-Nimakoh M, Carolan-Olah M, McCann TV. Barriers to obstetric care at health facilities in Sub-Saharan Africa-a systematic review protocol. Systematic reviews. 2015;4(1):54.

5. Ononokpono DN. Maternal health care in Nigeria: Do community factors moderate the effects of individual-level education and ethnic origin? Etude de la Population Africaine. 2015;29(1):1554.

6. Nyamtema AS, Mwakatundu N, Dominico S, Mohamed H, Pemba S, Rumanyika R, Nzabuhakwa C. Enhancing Maternal and Perinatal Health in Under-Served Remote Areas in Sub-Saharan Africa: A Tanzanian Model. PLoS One. 2016;11(3):e0151419.

7. Chola L, Pillay Y, Barron P, Tugendhaft A, Kerber K, Hofman K. Cost and impact of scaling up interventions to save lives of mothers and children: taking South Africa closer to MDGs 4 and 5. Glob Health Action. 2015:8:1-14.

8. Sherry K. Disability and rehabilitation : essential considerations for equitable, accessible and poverty-reducing health care in South Africa2014 [cited ["Sherry, Kate - University of Cape Town"]:[89-99 pp.]. Available from: http:// reference.sabinet.co.za/webx/access/electronic_journals/healthr/healthr_ 20142015 a9.pdf. Accessed on 16 Dec 2016

9. Ahumuza SE, Matovu JKB, Ddamulira JB, Muhanguzi FK. Challenges in accessing sexual and reproductive health services by people with physical disabilities in Kampala. Uganda Reproductive Health. 2014;11(1):59.

10. Bremer K, Cockburn L, Ruth A. Reproductive health experiences among women with physical disabilities in the Northwest Region of Cameroon. Int J Gynaecol Obstet. 2010;108(3):211-3.

11. Smith E, Murray SF, Yousafzai AK, Kasonka L. Barriers to accessing safe motherhood and reproductive health services: the situation of women with disabilities in Lusaka. Zambia Disability Rehabilitation. 2004;26(2):121-7.

12. Graves A. A model for assessment of potential geographical accessibility: a case for GIS. Online J Rural Nurs Health Care. 2009:9(1):46.

13. Levesque JF, Harris MF, Russell G. Patient-centred access to health care: conceptualising access at the interface of health systems and populations. Int J Equity Health. 2013;12(1):18.

14. Bradbury-Jones C, Breckenridge JP, Devaney J, Duncan F, Kroll T, Lazenbatt A, et al. Priorities and strategies for improving disabled women's access to maternity services when they are affected by domestic abuse: a multi-method study using concept maps. BMC Pregnancy and Childbirth. 2015;15(350):350.

15. Hwang K, Johnston M, Tulsky D, Wood K, Dyson-Hudson T, Komaroff E. Access and coordination of health care service for people with disabilities. J Disability Policy Studies. 2009;20(1):28-34.

16. Morrison J, Basnet M, Budhathoki B, Adhikari D, Tumbahangphe K, Manandhar D, et al. Disabled women's maternal and newborn health care in rural Nepal: a qualitative study. Midwifery. 2014:30(11):1132-9.

17. Lawler D, Lalor J, Begley C. Access to maternity services for women with a physical disability: a systematic review of the literature. Int J Childbirth. 2013;3(4):203.

18. Colquhoun HL, Levac D, O'Brien KK, Straus S, Tricco AC, Perrier L, et al. Scoping reviews: time for clarity in definition, methods, and reporting. J Clin Epidemiol. 2014;67(12):1291-4

19. Arksey H, O'Malley L. Scoping studies: towards a methodological framework Int J Soc Res Methodol. 2005:8(1):19-32.

20. Castleberry A. NVivo 10 [software program]. Version 10. QSR International; 2012. American journal of pharmaceutical education. 2014;78(1)

21. Pluye P, Robert E, Cargo M, Bartlett G, O'Cathain A, Griffiths F, et al. Proposal: a mixed methods appraisal tool for systematic mixed studies reviews. Montreal: McGill University, Department of Family Medicine; 2011. Mixed methods appraisal tool (MMAT) version 2011.

\section{Submit your next manuscript to BioMed Central and we will help you at every step:}

- We accept pre-submission inquiries

- Our selector tool helps you to find the most relevant journal

- We provide round the clock customer support

- Convenient online submission

- Thorough peer review

- Inclusion in PubMed and all major indexing services

- Maximum visibility for your research

Submit your manuscript at www.biomedcentral.com/submit
Biomed Central 